\title{
Identifying Target Risk Factors Using Population Attributable Risks of Ischemic Stroke by Age and Sex
}

\author{
Tai Hwan Park, ${ }^{a}$ Youngchai Ko, ${ }^{\text {b }}$ Soo Joo Lee, ${ }^{b}$ Kyung Bok Lee, ${ }^{c}$ Jun Lee, ${ }^{d}$ Moon-Ku Han, ${ }^{e}$ \\ Jong-Moo Park, ${ }^{\mathrm{f}}$ Yong-Jin Cho, ${ }^{\mathrm{g}}$ Keun-Sik Hong, ${ }^{\mathrm{g}}$ Dae-Hyun Kim, ${ }^{\mathrm{h}} \mathrm{Jae}-\mathrm{Kw}$ an Cha, ${ }^{\mathrm{h}} \mathrm{Mi}$-Sun Oh, ${ }^{\mathrm{i}}$ \\ Kyung-Ho Yu, ${ }^{i}$ Byung-Chul Lee, ${ }^{i}$ Byung-Woo Yoon, ${ }^{j}$ Ji Sung Lee, ${ }^{k}$ Juneyoung Lee, ${ }^{1}$ Hee-Joon Bae ${ }^{e}$ \\ ${ }^{a}$ Department of Neurology, Seoul Medical Center, Seoul, Korea \\ bDepartment of Neurology, Eulji University Hospital, Eulji University School of Medicine, Daejeon, Korea \\ 'Department of Neurology, Soonchunhyang University College of Medicine, Seoul, Korea \\ dDepartment of Neurology, Yeungnam University Hospital, Daegu, Korea \\ e Department of Neurology, Seoul National University Bundang Hospital, Seoul National University College of Medicine, Seongnam, Korea \\ ${ }^{\mathrm{f}}$ Department of Neurology, Eulji General Hospital, Eulji University, Seoul, Korea \\ ${ }^{g}$ Department of Neurology, Ilsan Paik Hospital, Inje University, Ilsan, Korea \\ hepartment of Neurology, Dong-A University Hospital, Pusan, Korea \\ i Department of Neurology, Hallym University Sacred Heart Hospital, Anyang, Korea \\ 'Department of Neurology, Seoul National University Hospital, Seoul, Korea \\ ${ }^{k}$ Clinical Research Center, Asan Medical Center, Seoul, Korea \\ 'Department of Biostatistics, Korea University College of Medicine, Seoul, Korea
}

Background and Purpose Estimating age- and sex-specific population attributable risks (PARs) of major risk factors for stroke may be a useful strategy to identify risk factors for targeting preventive strategies.

Methods For this case-control matched study, consecutive patients aged 18-90 years and admitted to nine nationwide hospitals with acute ischemic stroke between December 2008 and June 2010, were enrolled as cases. Controls, individually matched by age and sex, were chosen from the 4th Korean National Health \& Nutrition Examination Survey (2008-2010). Based on odds ratios and prevalence, standardized according to the age and sex structure of the Korean population, PARs of major risk factors were estimated according to age (young, $\leq 45$; middle-aged, 46-65; and elderly, $\geq 66$ years) and sex subgroups.

Results In 4,743 matched case-control sets, smoking (PAR, 45.1\%) was the greatest contributing risk factor in young men, followed by hypertension (28.5\%). In middle-aged men, the greatest contributing factors were smoking (37.4\%), hypertension (22.7\%), and diabetes $(14.6 \%)$, whereas in women the greatest factors were hypertension $(22.7 \%)$ and stroke history (10.6\%). In the elderly, hypertension was the leading factor in men (23.7\%) and women (23.4\%). Other noticeable factors were stroke history (men, 19.7\%; women, 17.3\%) and diabetes (men, 12.5\%; women, 15.1\%). In young women, risk factors with a PAR greater than $10 \%$ were not found.

Conclusions Smoking cessation in young people and hypertension and diabetes control in older people may be effective in reducing the burden of stroke on the population. In the elderly, secondary prevention could also be emphasized.
Correspondence: Hee-Joon Bae Department of Neurology, Stroke Center, Seoul National University Bundang Hospital, 82 Gumi-ro 173beon-gil, Bundang-gu, Seongnam 13620, Korea Tel: +82-31-787-7467

Fax: +82-31-787-4059

E-mail: braindoc@snu.ac.kr

Received: April 24, 2015

Revised: July 24, 2015

Accepted: July 24, 2015

This work was supported by a grant from the Korea Healthcare Technology RCtD Project, Ministry for Health, Welfare \& Family Affairs, Republic of Korea (HI10C2020).

The authors have no financial conflicts of interest.

Keywords Population attributable risk; Ischemic stroke; Risk factor

Copyright $\odot 2015$ Korean Stroke Society

This is an Open Access article distributed under the terms of the Creative Commons Attribution Non-Commercial License (http://creativecommons.org/licenses/by-nc/3.0/) which permits unrestricted non-commercial use, distribution, and reproduction in any medium, provided the original work is properly cited. 


\section{Introduction}

Stroke is a leading cause of disability and death in most countries. ${ }^{1}$ Control of modifiable risk factors is the most effective approach to decreasing the burden of stroke..$^{2-4}$ According to an international case-controlled study (INTERSTROKE), ten risk factors account for about $90 \%$ of the risk of stroke, and our efforts at stroke prevention should be concentrated on reducing blood pressure (BP) and promoting smoking cessation, physical activity, and a healthy diet. ${ }^{5}$

However, the impact of modifiable risk factors on stroke incidence is not equal between different ethnic groups, sexes, or age groups. ${ }^{1,6-9}$ For example, in the INTERSTROKE study, hypertension was more strongly associated with strokes in women than in men, and in people aged 45 years or younger than in those aged 45 years or older. ${ }^{5}$ The recommended strategies for preventing strokes in women with hypertension are different from those in men with hypertension, ${ }^{7}$ and the optimal target $\mathrm{BP}$ is higher in people aged 60 years or older than in those less than 60 years. ${ }^{10}$ Additionally, the risk of strokes in diabetic patients varies with age $^{8}$ and sex. ${ }^{9}$ Therefore, stroke prevention strategies in a specific populations would be more effective if they were designed based on knowledge of the population attributable risks (PARs) of individual risk factors in each age- and sex-specific subpopulation because the PAR indicates the proportion of a disease that could be prevented by eliminating the risk factor of interest in a specific population. ${ }^{11}$

The burden of stroke, as compared to coronary heart disease (CHD), is disproportionately high in East Asian countries, including China, Japan, and South Korea. ${ }^{12}$ Furthermore, these countries are the world's fastest aging countries; ${ }^{13}$ their burden of stroke is therefore expected to increase substantially in the near future unless effective prevention strategies are launched. However, there is a paucity of information about age- and sexspecific PARs of the major risk factors in Asian populations. ${ }^{14-17}$

In this study, we aimed to estimate the age- and sex-specific PARs of the major risk factors for strokes in the Korean population.

\section{Methods}

\section{Recruitment of cases}

The Clinical Research Center for Stroke (CRCS) project sponsored by the Korean Government was established in 2006 to facilitate a multicenter collaborative stroke research program in Korea and to develop and implement clinical practice guidelines for stroke treatment and prevention. The fifth section of CRCS (CRCS-5), which was dedicated to epidemiologic research, constructed a web-based, prospective stroke registry da- tabase and, in April 2008, began to collect clinical information on patients hospitalized for strokes. Using the CRCS-5 registry database, cases were selected from acute ischemic stroke patients admitted within 7 days of onset. Ischemic stroke was defined as acute focal neurological deficits and relevant ischemic brain lesions found on computed tomography or diffusion-weighted magnetic resonance imaging. Details of the CRCS-5 database have been reported elsewhere. ${ }^{18}$

This study focused on ischemic stroke because 1) consecutive registration of hemorrhagic stroke patients was not guaranteed at some centers and 2) acute and hemorrhagic strokes have fairly different risk factor profiles. ${ }^{19}$

Among the 6,023 patients hospitalized between December 1, 2008 and June 30, 2010, we excluded 274 who were admitted $\geq 7$ days after stroke onset, 135 with hemorrhagic stroke, and 340 with a transient ischemic attack. Patients younger than 19 years or older than 90 years were also excluded because matched control cases of these age ranges were rare in the Korea National Health and Nutrition Examination Survey (KNHANES) database. Patients with missing height or weight information ( $\mathrm{n}=$ 101) were also excluded. Ultimately, 5,107 cases were eligible for matching (Figure 1A).

\section{Recruitment of controls}

The 4th (2007-2009) and 5th (2010-2012) KNHANES was conducted by the Korean Center for Disease Control to investigate the health status of the Korean population through annual nationwide representative sampling. ${ }^{20}$ The KNHANES employed a stratified, multi-stage probability sampling design; subjects were selected from sampling units predicated on geographical area, sex, and age, based on household registers. Among the subjects surveyed in 2008,2009, and 2010, 19,435 subjects, aged 19-90 years with no missing information about risk factors of interest, were selected for matching (Figure 1B).

\section{Matching process}

Each case was matched to one control by age ( \pm 3 years) and sex. Despite limiting the age range to $19-90$ years, 364 elderly patients were excluded due to a lack of corresponding controls. Therefore, 4,743 case-control sets were used for the analysis.

The CRCS-5 registry got approval for collection and analysis of anonymized clinical data without patients' consent for the purpose of monitoring and improving the quality of stroke care from the institutional review boards (IRBs) of the participating centers. We obtained additional approval for the use of the registry database and the KNHANES database to conduct this study. 


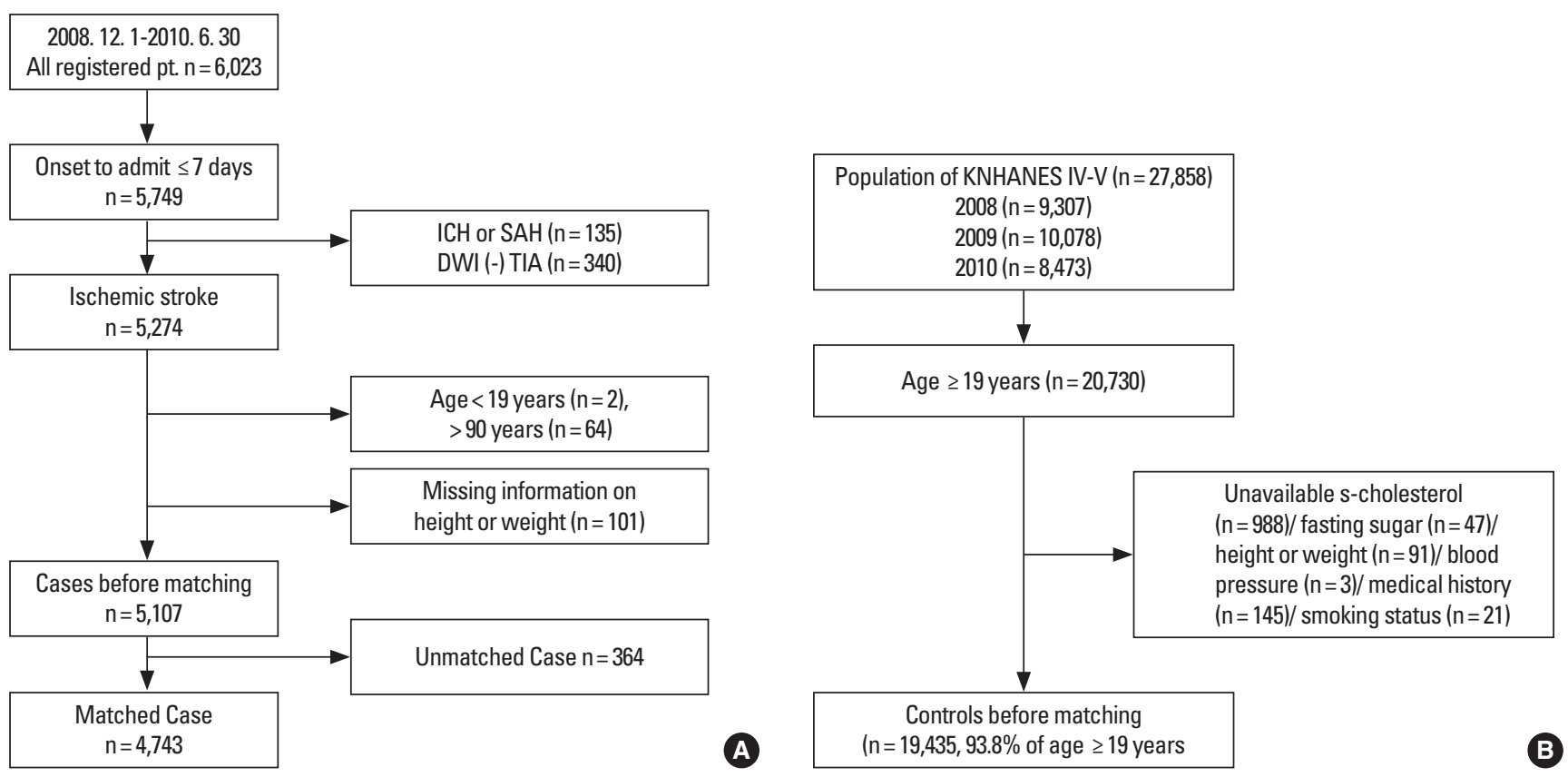

Figure 1. Flow diagram for cases (A) and controls (B). ICH, intracerebral hemorrhage; SAH, subarachnoid hemorrhage; DWI, diffusion-weighted image; TIA, transient ischemic attack; KNHANES, Korea National Health and Nutrition Examination Survey.

\section{Definition and selection of vascular risk factors}

Risk factors of interest were chosen based on their relative importance in the primary prevention guidelines ${ }^{4}$ and the comparability of their definitions between the CRCS-5 registry and the KNHANES. Hypertension, diabetes, hypercholesterolemia, smoking, prior stroke, $\mathrm{CHD}$, and obesity were selected. Despite its importance as a stroke risk factor, atrial fibrillation was not included because the KNHANES did not gather information on it.

Hypertension was defined as a mean systolic BP $\geq 140 \mathrm{mmHg}$ or a mean diastolic BP $\geq 90 \mathrm{mmHg}$ in repeated measures, prior use of antihypertensive medications, or a self-reported physician diagnosis. BP measurements used for the diagnosis of hypertension in the cases were obtained after patients were medically and neurologically stabilized. Diabetes was defined as a fasting blood glucose $\geq 126 \mathrm{mg} / \mathrm{dL}$, prior use or prescription-at-discharge of hypoglycemic medications, or a self-reported physician diagnosis. Hypercholesterolemia was defined as prior use of lipid lowering agents, fasting total serum cholesterol $>240 \mathrm{mg} / \mathrm{dL}$, or a selfreported physician diagnosis. For the cases, smoking was defined as a current smoker who had smoked at least one cigarette in the last month, whereas for the controls it was defined as a current smoker with a lifetime history of smoking $\geq 100$ cigarettes. Prior stroke was defined as a stroke history diagnosed by a physician. $\mathrm{CHD}$ was defined as a self-reported physician diagnosis for angina pectoris or myocardial infarction. A history of coronary intervention (angioplasty and/or stent insertion) and of coronary arterial bypass graft surgery was added to the definition of $\mathrm{CHD}$ only for the cases. Obesity was diagnosed according to the World Health Organization guidelines. Subjects whose body mass index (BMI) was $<18.5 \mathrm{~kg} / \mathrm{m}^{2}, 25$ to $29.9 \mathrm{~kg} / \mathrm{m}^{2}$, or $\geq 30 \mathrm{~kg} / \mathrm{m}^{2}$ were classified as underweight, overweight, or obese, respectively.

\section{Statistical analysis}

Continuous variables are presented as means \pm SD or medians (interquartile range, $I Q R$ ), and categorical variables are reported as proportions. Before estimating the PAR of a risk factor, we determined the strength of the association between the risk factor and ischemic strokes in all subjects and within each age and sex subgroup by using odds ratios (ORs) and 95\% confidence intervals (CIs). Conditional logistic regression was applied to the estimation of ORs and CIs for the matched sets and adjustments were made for risk factors of interest and age. PARs of individual risk factors were calculated using the following formula: $P A R=P R(O R-1) /[1+P R(O R-1)]$, ${ }^{21}$ where $P R$ represents the age- and sex-specific prevalence of a risk factor in the Korean population, estimated from the age- and sex-specific prevalence in the 4th KNHANES and standardized according to the age and sex structure of the general population in the 2010 Census of Korea (Table 1). OR represents the age- and sex-specific OR obtained as described above. CIs of the PARs were estimated using a substitution method. ${ }^{22}$

To estimate age-specific PARs, age was categorized into 3 groups; $\leq 45$ years (young), 46 to 65 years (middle-aged), and $\geq 66$ years (elderly). In men and women, age-specific PARs were 
Table 1. Prevalence of individual risk factors in the general population according to age group

\begin{tabular}{lcccc}
\hline & \multicolumn{4}{c}{ Prevalence $\%$, $(95 \% \mathrm{Cl})$} \\
\cline { 2 - 5 } & $20-45$ years & $46-65$ years & Total \\
\hline Hypertension & $8.09(7.41-8.77)$ & $34.50(33.15-35.84)$ & $58.98(57.05-60.91)$ & $23.98(23.13-24.83)$ \\
Diabetes & $2.78(2.38-3.18)$ & $12.90(11.98-13.81)$ & $20.89(19.21-22.56)$ & $8.68(8.20-9.15)$ \\
Smoking & $33.27(32.11-34.44)$ & $26.62(25.35-27.89)$ & $16.54(15.06-18.01)$ & $28.73(27.92-29.54)$ \\
Stroke history & $0.11(0.04-0.18)$ & $1.86(1.49-2.24)$ & $6.00(5.20-6.79)$ & $1.51(1.35-1.68)$ \\
Coronary heart disease & $0.33(0.20-0.47)$ & $2.71(2.29-3.14)$ & $5.70(4.91-6.48)$ & $1.87(1.68-2.07)$ \\
Hypercholesterolemia & $5.45(4.93-5.98)$ & $16.32(15.23-17.41)$ & $17.31(15.74-18.87)$ & $10.74(10.22-11.26)$ \\
Obesity, BMl (kg/m²) & & & & \\
$25.0-29.9$ & $23.77(22.75-24.79)$ & $33.44(32.24-34.64)$ & $28.96(27.20-30.72)$ & $27.73(27.00-28.47)$ \\
$\geq 30$ & $4.23(3.75-4.71)$ & $3.66(3.15-4.16)$ & $3.31(2.62-4.00)$ & $3.91(3.58-4.25)$ \\
$<18.5$ & $6.42(5.81-7.03)$ & $2.04(1.61-2.46)$ & $4.76(4.04-5.48)$ & $4.72(4.35-5.09)$ \\
$18.5 \leq,<25$ & $65.58(64.42-66.74)$ & $60.86(59.59-62.14)$ & $62.97(62.21-64.74)$ & $63.64(62.81-64.47)$ \\
\hline
\end{tabular}

"Age- and sex-standardized prevalence using a direct standardization method.

$\mathrm{Cl}$, confidence interval; BMl, body mass index.

Table 2. Prevalence of individual risk factors in men of the general population according to age group

\begin{tabular}{lcccc}
\hline & \multicolumn{4}{c}{ Prevalence \%, $95 \%$ Cl) } \\
\cline { 2 - 5 } & $20-45$ years & $46-65$ years & Total \\
\hline Hypertension & $12.41(11.20-13.61)$ & $37.33(35.24-39.43)$ & $51.59(48.65-54.54)$ & $25.30(24.16-26.44)$ \\
Diabetes & $3.16(2.55-3.77)$ & $15.49(14.00-16.97)$ & $20.20(18.04-22.36)$ & $9.27(8.59-9.95)$ \\
Smoking & $57.26(55.56-58.97)$ & $48.76(46.54-50.98)$ & $32.00(29.04-34.96)$ & $51.52(50.21-52.82)$ \\
Stroke history & $0.16(0.04-0.28)$ & $2.21(1.60-2.83)$ & $7.69(6.32-9.05)$ & $1.71(1.45-1.97)$ \\
Coronary heart disease & $0.46(0.23-0.69)$ & $2.85(2.18-3.51)$ & $6.35(5.11-7.60)$ & $1.94(1.65-2.23)$ \\
Hypercholesterolemia & $7.26(6.36-8.16)$ & $13.59(12.10-15.09)$ & $9.75(7.86-11.63)$ & $9.69(8.93-10.44)$ \\
Obesity, BMl (kg/m²) & & & & \\
$25.0-29.9$ & $31.83(30.15-33.51)$ & $36.84(34.97-38.70)$ & $22.83(20.47-25.18)$ & $32.51(31.36-33.65)$ \\
$\geq 30$ & $4.76(3.99-5.53)$ & $2.77(2.08-3.45)$ & $1.23(0.65-1.82)$ & $3.69(3.19-4.19)$ \\
$<18.5$ & $3.29(2.63-3.95)$ & $1.97(1.43-2.51)$ & $6.55(5.21-7.89)$ & $3.21(2.77-3.66)$ \\
$18.5 \leq,<25$ & $60.12(58.37-61.87)$ & $58.43(56.52-60.33)$ & $69.39(66.79-71.99)$ & $60.60(59.40-61.80)$ \\
\hline
\end{tabular}

"Age standardized prevalence using a direct standardization method.

$\mathrm{Cl}$, confidence interval; BMI, body mass index.

estimated by using the age-standardized prevalence within each age group (Tables 2, 3). A two-sided $P$ value $<0.05$ was considered statistically significant. All statistical analyses were performed with SAS version 9.3 (SAS, Cary, NC, USA).

\section{Results}

Of the 4,743 cases in this study, $60 \%$ were men, and the mean age was $63.7 \pm 11.6$ years in men and $69.2 \pm 11.0$ years in women. The proportion of cases $\leq 45$ years, $46-65$ years, and $\geq 66$ years were $5.7 \%, 35.6 \%$, and $58.7 \%$, respectively. The median National Institute of Health Stroke Scale score was 4 (IQR, 2-8). Hypertension was the most frequent risk factor $(63.6 \%$ in men, $70.1 \%$ in women), followed by diabetes and smoking (Table 4).

When combining all age groups, hypertension, diabetes, stroke history, and CHD related to an increased risk of strokes in both sexes, whereas hypercholesterolemia and smoking were related to an increased risk in men but not in women (Table 4). Being underweight increased the risk of strokes in women while being overweight was protective in both sexes.

Age- and sex-specific ORs and PARs of individual risk factors are presented in Table 5. The OR of hypertension was highest in the young and decreased with age in both sexes. However, its PAR was similar in most of age and sex subgroups because the prevalence of hypertension increased with age (Tables 1-3). Approximately one fourth of strokes were attributed to hypertension across all age groups except for young women.

For cases involving diabetes, the OR was highest in young men but the PAR was highest in elderly women. The OR decreased with age in men, but was similar between middle-aged and elderlywomen.

Stroke history was a strong risk factor in most age and sex subgroups, especially in the elderly, where the PAR was $19.7 \%$ in elderly men and $17.3 \%$ in women. The OR and PAR of CHD 
Table 3. Prevalence of individual risk factors in women of the general population according to the age group

\begin{tabular}{lcccc}
\hline & \multicolumn{4}{c}{ Prevalence $\%$, (95\% CI) } \\
\cline { 2 - 5 } & $20-45$ years & $46-65$ years & T66 years & Total \\
\hline Hypertension & $3.62(3.05-4.20)$ & $31.72(29.98-33.47)$ & $63.92(61.50-66.34)$ & $22.72(21.72-23.72)$ \\
Diabetes & $2.38(1.86-2.90)$ & $10.37(9.25-11.49)$ & $21.35(19.06-23.63)$ & $8.11(7.48-8.73)$ \\
Smoking & $8.44(7.39-9.50)$ & $4.98(4.09-5.88)$ & $6.19(4.92-7.46)$ & $6.93(6.26-7.60)$ \\
Stroke history & $0.07(0.00-0.14)$ & $1.52(1.13-1.90)$ & $4.86(3.92-5.81)$ & $1.33(1.13-1.53)$ \\
Coronary heart disease & $0.20(0.09-0.31)$ & $2.58(2.04-3.13)$ & $5.25(4.17-6.34)$ & $1.81(1.54-2.08)$ \\
Hypercholesterolemia & $3.59(2.99-4.18)$ & $18.99(17.53-20.45)$ & $22.36(20.07-24.66)$ & $11.74(11.04-12.44)$ \\
Obesity, BMl (kg/m²) & & & & \\
$25.0-29.9$ & $15.44(14.21-16.66)$ & $30.13(28.53-31.72)$ & $33.06(30.79-35.33)$ & $23.17(22.21-24.13)$ \\
$\geq 30$ & $3.68(3.06-4.58)$ & $4.53(3.73-5.32)$ & $4.70(3.61-5.78)$ & $4.13(3.68-4.58)$ \\
$<18.5$ & $9.66(8.60-10.71)$ & $2.10(1.47-2.73)$ & $3.56(2.76-4.36)$ & $6.16(5.54-6.78)$ \\
$18.5 \leq,<25$ & $71.23(69.75-72.70)$ & $63.24(61.50-64.99)$ & $58.68(56.39-60.97)$ & $66.54(65.48-67.61)$ \\
\hline
\end{tabular}

"Age standardized prevalence using a direct standardization method.

$\mathrm{Cl}$, confidence interval; BMI, body mass index.

Table 4. Frequency of individual risk factors in cases and controls

\begin{tabular}{|c|c|c|c|c|c|c|}
\hline & \multicolumn{3}{|c|}{ Men, $n(\%)$} & \multicolumn{3}{|c|}{ Women, $n(\%)$} \\
\hline & Cases $(n=2,846)$ & Controls $(n=2,846)$ & Adjusted OR (95\% CI) & Cases $(n=1,897)$ & Controls $(n=1,897)$ & Adjusted OR (95\% Cl) \\
\hline Hypertension & $1,811(63.6)$ & $1,349(47.4)$ & $1.76(1.55-2.00)$ & $1,329(70.1)$ & $1,067(56.2)$ & $1.64(1.39-1.95)$ \\
\hline Diabetes & $954(33.5)$ & $526(18.5)$ & $1.89(1.63-2.19)$ & $626(33.0)$ & $367(19.3)$ & $1.83(1.53-2.19)$ \\
\hline Hypercholesterolemia & $675(23.7)$ & 422 (14.8) & $1.38(1.18-1.62)$ & $541(28.5)$ & $455(24.0)$ & 1.07 (0.89-1.27) \\
\hline Smoking & $1,286(45.2)$ & 911 (32.0) & $2.03(1.78-2.31)$ & $111(5.9)$ & $108(5.7)$ & $1.26(0.92-1.74)$ \\
\hline Stroke history & $641(22.5)$ & $140(4.9)$ & $4.96(3.97-6.17)$ & $406(21.4)$ & $75(4.0)$ & $6.21(4.56-8.45)$ \\
\hline Coronary heart disease & $291(10.2)$ & $146(5.1)$ & $1.76(1.38-2.25)$ & $191(10.1)$ & $70(3.7)$ & $2.65(1.89-3.72)$ \\
\hline \multicolumn{7}{|l|}{$\mathrm{BMI}\left(\mathrm{kg} / \mathrm{m}^{2}\right)$} \\
\hline$<18.5$ & $110(3.9)$ & $120(4.2)$ & $0.87(0.63-1.19)$ & $120(6.3)$ & $66(3.5)$ & $1.87(1.29-2.70)$ \\
\hline $18.5-24.9$ & $1,874(65.8)$ & $1,844(64.8)$ & 1 & $1,188(62.6)$ & $1,142(60.2)$ & 1 \\
\hline $25.0-29.9$ & 792 (27.8) & $821(28.8)$ & $0.85(0.74-0.98)$ & $504(26.6)$ & $607(32.0)$ & $0.68(0.57-0.80)$ \\
\hline$\geq 30.0$ & $70(2.5)$ & $61(2.1)$ & $0.77(0.51-1.17)$ & $85(4.5)$ & $82(4.3)$ & $0.80(0.55-1.15)$ \\
\hline
\end{tabular}

OR was adjusted for age and other risk factors of interest.

$\mathrm{OR}$, odds ratio; $\mathrm{Cl}$, confidence interval; $\mathrm{BMl}$, body mass index.

were highest in elderly women, which on average, were twice those in elderly men ( 2.99 vs. $1.67 ; 9.5 \%$ vs. $4.1 \%$ ).

The increased risk of strokes due to smoking was highest in middle-aged women (OR, 2.66; 95\% CI, 1.39-5.12). However, the PAR for strokes due to smoking was highest in young men. About half of strokes in young men and more than one third of strokes in middle-aged men were attributed to smoking. The magnitude of the increased risk and the contribution to stroke incidence by smoking were mitigated in elderly men.

Hypercholesterolemia increased the risk of strokes only in elderly men. The association of BMI with strokes was inconsistent throughout all age and sex subgroups. Being underweight did not increase the risk in any subgroup. Obesity increased the risk only in young women. Being overweight in middle-aged men and obesity in middle-aged women were both associated with a decreased risk of strokes.

To summarize the major contributions of the risk factors among age and sex subgroups, smoking (PAR, 45.1\%) and hypertension (28.5\%) were the major contributing risk factors in young men. There were no risk factors with a PAR greater than $10 \%$ in young women. In middle-aged men, smoking was still the greatest risk factor (37.4\%), followed by hypertension (22.7\%). In middleaged women, hypertension was the greatest risk factor (22.7\%). The contributions of diabetes and stroke history were larger in the middle-aged than in the young.

In the elderly, the contribution of hypertension was similar in both sexes and not different from that in the middle-aged. The contribution of stroke history and diabetes was also remarkable in the elderly.

\section{Discussion}

Our study shows that the contributions of the major risk factors to ischemic strokes differ by age and sex. Therefore, tai- 
Table 5. Odds ratio and population attributable risk in age- and sex-specific subgroups

\begin{tabular}{|c|c|c|c|c|c|}
\hline \multirow{2}{*}{ Risk factor } & \multirow{2}{*}{ Age groups (N/n) } & \multicolumn{2}{|c|}{ Men } & \multicolumn{2}{|c|}{ Women } \\
\hline & & $\mathrm{OR}^{*}(95 \% \mathrm{Cl})$ & $\operatorname{PAR}^{\dagger}(95 \%$ CI), $\%$ & $\mathrm{OR}^{*}(95 \% \mathrm{Cl})$ & $\operatorname{PAR}^{\dagger}(95 \% \mathrm{CI}), \%$ \\
\hline \multirow[t]{3}{*}{ Hypertension } & $\leq 45 \mathrm{yr}(410 / 132)$ & $4.21(2.26-7.83)$ & $28.45(13.51-45.86)$ & $2.57(0.78-8.53)$ & $5.39(-0.82-21.45)$ \\
\hline & $46-65$ yr $(2,430 / 946)$ & $1.79(1.47-2.17)$ & 22.66 (14.93-30.38) & $1.93(1.41-2.62)$ & $22.69(11.61-33.95)$ \\
\hline & $\geq 66$ yr $(2,852 / 2,716)$ & $1.60(1.33-1.92)$ & $23.67(14.70-32.21)$ & $1.48(1.20-1.82)$ & $23.40(11.44-34.31)$ \\
\hline \multirow[t]{3}{*}{ Diabetes } & $\leq 45 \mathrm{yr}(410 / 132)$ & $2.78(1.14-6.80)$ & $5.32(0.43-15.49)$ & $2.14(0.38-11.98)$ & $2.65(-1.49-20.72)$ \\
\hline & $46-65$ yr $(2,430 / 946)$ & $2.10(1.68-2.63)$ & 14.56 (9.52-20.12) & $1.81(1.25-2.63)$ & $7.76(2.49-14.47)$ \\
\hline & $\geq 66$ yr $(2,852 / 2,716)$ & $1.71(1.39-2.10)$ & $12.48(7.28-18.11)$ & $1.83(1.49-2.25)$ & $15.07(9.43-21.10)$ \\
\hline \multirow[t]{3}{*}{ Smoking } & $\leq 45 \mathrm{yr}(410 / 132)$ & $2.43(1.46-4.07)$ & 45.05 (20.74-63.72) & $1.74(0.36-8.48)$ & $5.89(-5.74-38.72)$ \\
\hline & $46-65$ yr $(2,430 / 946)$ & $2.22(1.83-2.69)$ & 37.36 (28.91-45.24) & $2.66(1.39-5.12)$ & $7.65(1.88-17.04)$ \\
\hline & $\geq 66$ yr $(2,852 / 2,716)$ & $1.77(1.45-2.15)$ & 16.73 (12.64-26.95) & $0.84(0.57-1.26)$ & $-0.98(-2.75-1.55)$ \\
\hline \multirow[t]{3}{*}{ Hypercholesterolemia } & $\leq 45$ yr $(410 / 132)$ & $1.65(0.84-3.22)$ & $4.49(-1.17-13.90)$ & $1.23(0.28-5.52)$ & $0.83(-2.66-13.94)$ \\
\hline & $46-65$ yr $(2,430 / 946)$ & $1.19(0.95-1.50)$ & $2.54(-0.70-6.32)$ & $0.85(0.61-1.19)$ & $-2.89(-7.95-3.41)$ \\
\hline & $\geq 66$ yr $(2,852 / 2,716)$ & $1.63(1.27-2.08)$ & $5.76(2.58-9.54)$ & $1.18(0.95-1.46)$ & $3.81(-1.15-9.29)$ \\
\hline \multirow[t]{3}{*}{ Stroke history } & $\leq 45 \mathrm{yr}(410 / 132)$ & 4.22 (0.68-26.08) & $0.51(-0.05-3.88)$ & $4.37(0.12-164.75)$ & $0.22(-0.06-9.65)$ \\
\hline & $46-65$ yr $(2,430 / 946)$ & $6.91(4.54-10.52)$ & $11.58(7.27-17.41)$ & $8.83(4.18-18.63)$ & $10.61(4.60-21.11)$ \\
\hline & $\geq 66$ yr $(2,852 / 2,716)$ & $4.18(3.21-5.46)$ & 19.66 (14.51-25.51) & $5.30(3.79-7.41)$ & $17.30(11.96-23.76)$ \\
\hline \multirow[t]{3}{*}{ Coronary heart disease } & $\leq 45 \mathrm{yr}(410 / 132)$ & $1.66(0.18-15.19)$ & $0.30(-0.38-6.13)$ & a & \\
\hline & $46-65$ yr $(2,430 / 946)$ & $1.84(1.21-2.80)$ & $2.34(0.59-4.87)$ & $1.95(0.97-3.93)$ & $2.40(-0.08-7.04)$ \\
\hline & $\geq 66$ yr $(2,852 / 2,716)$ & $1.67(1.23-2.28)$ & $4.10(1.44-7.50)$ & $2.99(2.02-4.43)$ & $9.45(5.06-15.26)$ \\
\hline \multicolumn{6}{|l|}{$\mathrm{BMI}\left(\mathrm{kg} / \mathrm{m}^{2}\right)$} \\
\hline \multirow[t]{3}{*}{$<18.5$} & $\leq 45 \mathrm{yr}(13 / 8)$ & $0.81(0.20-3.34)$ & $-0.62(-2.71-7.16)$ & $1.47(0.33-6.50)$ & $4.33(-6.89-34.68)$ \\
\hline & $46-65$ yr (58/23) & 1.32 (0.68-2.53) & $0.62(-0.63-2.93)$ & $0.95(0.39-2.33)$ & $1.87(-0.70-8.50)$ \\
\hline & $\geq 66$ yr (159/155) & $0.74(0.50-1.08)$ & $-1.76(-3.38-0.52)$ & $1.26(0.18-8.71)$ & $3.60(1.23-6.99)$ \\
\hline \multirow[t]{3}{*}{$25.0-29.9$} & $\leq 45$ yr (152/29) & $1.48(0.87-2.49)$ & $-13.16(-4.18-32.20)$ & $1.91(0.67-5.42)$ & $-0.82(-10.49-17.04)$ \\
\hline & $46-65$ yr (826/311) & $0.79(0.65-0.97)$ & $-8.38(-14.95--1.27)$ & $0.80(0.58-1.10)$ & $-6.45(-14.41-2.90)$ \\
\hline & $\geq 66$ yr $(635 / 771)$ & $0.84(0.68-1.04)$ & $-3.84(-8.01-0.95)$ & $0.88(0.40-1.91)$ & -14.41 (-19.66--8.54) \\
\hline \multirow[t]{3}{*}{$\geq 30.0$} & $\leq 45 \operatorname{yr}(27 / 9)$ & $1.31(0.47-3.70)$ & $1.47(-2.61-11.40)$ & $2.05(1.35-3.11)$ & $0.96(-3.10-22.12)$ \\
\hline & $46-65$ yr (57/36) & $0.67(0.36-1.25)$ & $-0.92(-1.81-0.70)$ & $0.62(0.50-0.76)$ & $-0.57(-2.79-3.96)$ \\
\hline & $\geq 66$ yr (47/122) & $0.75(0.37-1.54)$ & $-0.31(-0.79-0.66)$ & $0.73(0.47-1.13)$ & $-1.29(-2.55-0.60)$ \\
\hline
\end{tabular}

${ }^{*}$ OR was adjusted for age and other risk factors of interest; ${ }^{+}$PAR was calculated using the following formula: PAR=Pg (OR-1)/[1+Pg (OR-1)], where Pg represents risk factor prevalence in the general population, estimated from the prevalence in the portion of the population over 19 years old in the 4th KNHANES, with standardization to the age structure of the general population from the 2010 Census; ${ }^{a} 0 \mathrm{R}$ was not available due to the rarity of coronary heart disease in this age group.

$\mathrm{N}$ represents the number of men in each age group, $\mathrm{n}$ represents the number of women; $\mathrm{OR}$, odds ratio; PAR, population attributable risk; $\mathrm{Cl}$, confidence interval; $\mathrm{BMI}$, body mass index.

lored preventive strategies based on this knowledge may be an effective approach to stroke prevention at a population level.

Stroke incidence and mortality have declined over the past decades in developed countries. This could be explained by widespread implementation of public health programs for the control of hypertension, diabetes, and dyslipidemia, and the cessation of smoking. ${ }^{23,24}$ Stroke mortality declined by $34.2 \%$ in Korea from 2002 to $2011 .^{25}$ However, the declining trend in stroke mortality leveled out after 2011 , with only a $0.8 \%$ decrease over the next 3 years, which could be at least partly attributed to the fast-aging population. Thus, it is time to develop new preventive strategies using the knowledge obtained from the current study.

Although several studies have reported the PARs of individual risk factors for strokes in Korean population, ${ }^{26-28}$ only one study ${ }^{28}$ described the age- and sex-specific PARs. The relative risks used in that study were mostly obtained from non-Koreans, and therefore, might not reflect the properties of Korean populations. The estimated age- and sex-specific PARs in the current study indicate that there should be an emphasis on BP control in the entire population, on smoking cessation in young- and middle-aged men, on diabetes control in the middle-aged and elderly of both sexes, and on the secondary prevention of strokes in the elderly of both sexes.

Although hypertension is the greatest contributing risk factor for ischemic strokes, ${ }^{4}$ the proportion of stroke incidence attributable to hypertension varies depending on the demographic

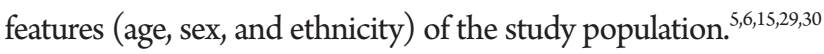
With the exception of young women, the age- and sex-specific PARs of hypertension (23\%-28\%) in the current study were greater than the PARs among non-Hispanic white (3\%) and black (16\%) populations but were smaller than the PAR among Hispanics (51\%), as reported in the recent Northern Manhattan Study. ${ }^{6}$ The contribution of hypertension to stroke incidence in Asian countries might have declined during the past decades. A 
recent cohort study in Japan reported that the PAR of hypertension decreased from $51 \%$ to $30 \%$ over 27 years. ${ }^{30}$ However, in order to sustain this declining trend we should pay attention to $\mathrm{BP}$ control in the elderly because of the rapid aging of populations in East Asian countries.

Given the high smoking rate in Asian men compared to other parts of the world, ${ }^{16}$ it may be no surprise that about one-third of ischemic strokes in men were attributed to smoking. However, in contrast to the findings of a recent meta-analysis, ${ }^{31}$ we could not find a significant association between smoking and strokes in young or elderly women. One possible explanation for the discrepancy is that this study included only ischemic stroke cases and smoking was associated with a greater risk for hemorrhagic strokes in women than in men. ${ }^{31}$ Additionally, our study might lack the statistical power to detect a significant association between smoking and strokes in young women due to the small sample size of this demographic subgroup. Only $21 \%$ of the general population in Korea is aware that smoking is a stroke risk factor. ${ }^{32}$ This underscores the urgent need to inform the public that smoking is an important risk factor for stroke, especially for young men in Korea, and to find a way to promote smoking cessation in this subpopulation.

We found a greater risk of stroke in relation to diabetes in young men (OR, 2.78) than in middle-aged (2.10) and elderly men (1.71). The increased risk of stroke among the younger diabetic men has been previously reported. ${ }^{8,33}$ However, we did not observe any sex differences in stroke risk related to diabetes, as reported in previous studies. ${ }^{9,34,35} \mathrm{~A}$ recent meta-analysis of 64 cohorts, including 775,385 individuals and 12,539 strokes, clearly showed an increased risk of stroke associated with diabetes in women; the pooled ratio of relative risks for women compared to men was 1.27 (95\% CI, 1.10-1.46). ${ }^{9}$ The above meta-analysis showed a lower, although statistically insignificant, relative risk of stroke for women compared to men in Asian than in nonAsian populations and that women have a lower risk of ischemic stroke than hemorrhagic stroke. This may explain, at least in part, the discrepancy between our study and the previous studies. The greatest PAR of diabetes was observed in elderly women, followed by the PARs in middle-aged and elderly men. These high PARs may be attributable to the higher prevalence in these age and sex subgroups (Tables 2, 3). Thus, the importance of diabetes control should be emphasized to alleviate the burden of stroke in the elderly of both sexes and in middle-aged men.

An increased risk associated with stroke history found in our study is consistent with the findings from Western populations where the risk of a second stroke is six to nine times greater than the risk of a first stroke. ${ }^{36,37}$ The proportion of stroke incidence attributable to stroke history was distinctly high in the elderly and the most plausible explanation is the high prevalence in this age group. In order to alleviate the stroke burden in elderly populations, in addition to strictly controlling factors such as BP and diabetes, improving patient adherence to antithrombotic drugs may also be effective as they are known to reduce the risk of recurrent vascular events. ${ }^{38}$

The contributions of hypercholesterolemia and CHD were not noticeable in our study population. The weak association of hypercholesterolemia with ischemic stroke in Koreans is concordant with the findings from a meta-analysis of 29 Asia-Pacific cohorts. ${ }^{17}$ The PAR for CHD was measurable only in the elderly, and was comparable to that found in Western populations. ${ }^{29,39} \mathrm{~A}$ stronger association of $\mathrm{CHD}$ with strokes in elderly women than in elderly men might be attributable to either a higher mean age or a higher prevalence of atrial fibrillation in women than in men. ${ }^{40}$ The inconsistent association of BMI with stroke risk throughout the age and sex subgroups in this study probably resulted from the small sample size of each subgroup and the modest effect of BMI on stroke risk. The protective effect of being overweight or obese, which was seen in middle-aged men and elderly women in this study, may be accounted for by an inverse relationship between obesity and better survival rates observed in some studies of CHD and stroke. ${ }^{41,42}$

This study has several limitations. First, there may be a concern about the national representativeness of both of the cases and the controls. Although national representativeness of stroke cases in the CRCS-5 registry has been commented on in a previous paper ${ }^{43}$ and the age and sex distribution of our cases was almost identical to that of a report from the National Health Insurance Review Board in Korea (Supplementary Table 1), the fact that most of the study sites were university hospitals could have introduced a selection bias. The CRCS-5 registry received a waiver of informed consent from the local IRBs and the completeness and consecutiveness of case registration was monitored aggressively through the monthly meetings of the steering committee. ${ }^{18}$ Therefore, a selection bias related to loss of cases in participating hospitals was less likely to occur. For controls, national representativeness was ensured by using the KNHANES data, the target population of which comprises nationally representative non-institutionalized civilians in Korea. ${ }^{20}$ Second, ORs observed in our study might be underestimated because our control group was not a stroke-free cohort, which limits the ability to measure the PAR of a prior stroke. However, the number of stroke survivors included was small (4\% of the control population) and likely had little effect on ORs. Third, differential recall and differences in risk factor definitions between the cases and controls might have led to biased estimates of ORs. For example, the risk of stroke history or $\mathrm{CHD}$ might be overestimated 
by a recall bias in the cases. As for smoking, the strength of association might be overestimated due to a looser definition for the cases. Fourth, subjects taking statins, even though they do not have hypercholesterolemia, might be misclassified as having it because prior use of lipid lowering agents was defined as hypercholesterolemia in this study. However, this misclassification was not likely to influence ORs because the same definition was applied to both the cases and the controls. Finally, we did not analyze other modifiable risk factors, such as atrial fibrillation, physical activity, or alcohol intake, due to the unavailability of these data for the cases and the controls. In particular, given that the risk factors evaluated in this study are primarily related to atherosclerosis, the contribution of the unmeasured risk factors to the risk of stroke might be expected to be greater in the young than in the elderly (Supplementary Table 2).

\section{Conclusions}

Measurements of the PARs of major risk factors for strokes by age and sex subgroups may be useful to help guide preventive strategies in public health programs. For example, we need to reinforce public campaigns and health education programs to reduce the smoking rate among young and middle aged populations. In the elderly, more medical surveillance to prevent stroke recurrence is required.

\section{Disclosures}

Park TH, Ko Y, Lee SJ, Lee KB, Lee J, Han MK, Park JM, Cho YJ, Hong KS, Kim DH, Cha JK, Oh MS, Yu KH, Lee BC, Yoon BW, Lee JS, Lee J report no disclosures.

Bae $\mathrm{HJ}$ is involved as a principal investigator, a member of the steering committee, and/or a site investigator of multicenter clinical trials or clinical studies sponsored by Otsuka Korea, Bayer Korea, Boehringer Ingelheim Korea, Handok Pharmaceutical Company, SK Chemicals, ESAI-Korea, Daewoong Pharmaceutical Co. Ltd, Daichi Sankyo, AstraZeneca Korea, Dong-A Pharmaceutical, and Yuhan Corporation; served as the consultant or scientific advisory board member for Bayer Korea, Boehringer Ingelheim Korea, BMS Korea, and Pfizer Korea, and received lecture honoraria from AstraZeneca Korea, Bayer Korea, BMS Korea, Coviden Korea, and Daichi Sankyo Korea (modest).

\section{References}

1. Feigin VL, Forouzanfar MH, Krishnamurthi R, Mensah GA, Connor M, Bennett DA, et al. Global and regional burden of stroke during 1990-2010: findings from the Global Burden of
Disease Study 2010. Lancet 2014;383:245-254.

2. Rothwell PM, Coull AJ, Giles MF, Howard SC, Silver LE, Bull LM, et al. Change in stroke incidence, mortality, case-fatality, severity, and risk factors in Oxfordshire, UK from 1981 to 2004 (Oxford Vascular Study). Lancet 2004;363:1925-1933.

3. Gorelick PB. Stroke prevention. Arch Neurol 1995;52:347-355.

4. Meschia JF, Bushnell C, Boden-Albala B, Braun LT, Bravata $\mathrm{DM}$, Chaturvedi $\mathrm{S}$, et al. Guidelines for the primary prevention of stroke: a statement for healthcare professionals from the American Heart Association/American Stroke Association. Stroke 2014;45:3754-3832.

5. O’Donnell MJ, Xavier D, Liu L, Zhang H, Chin SL, Rao-Melacini $\mathrm{P}$, et al. Risk factors for ischaemic and intracerebral haemorrhagic stroke in 22 countries (the INTERSTROKE study): a case-control study. Lancet 2010;376:112-123.

6. Willey JZ, Moon YP, Kahn E, Rodriguez CJ, Rundek T, Cheung $\mathrm{K}$, et al. Population attributable risks of hypertension and diabetes for cardiovascular disease and stroke in the northern Manhattan study.J Am Heart Assoc. 2014;3:e001106.

7. Bushnell C, McCullough LD, Awad IA, Chireau MV, Fedder $\mathrm{WN}$, Furie $\mathrm{KL}$, et al. Guidelines for the prevention of stroke in women: a statement for healthcare professionals from the American Heart Association/American Stroke Association. Stroke 2014;45:1545-1588.

8. Khoury JC, Kleindorfer D, Alwell K, Moomaw CJ, Woo D, Adeoye $\mathrm{O}$, et al. Diabetes mellitus: a risk factor for ischemic stroke in a large biracial population. Stroke 2013;44:1500-1504.

9. Peters SA, Huxley RR, Woodward M. Diabetes as a risk factor for stroke in women compared with men: a systematic review and meta-analysis of 64 cohorts, including 775,385 individuals and 12,539 strokes. Lancet 2014;383:1973-1980.

10. James PA, Oparil S, Carter BL, Cushman WC, Dennison-Himmelfarb C, Handler J, et al. 2014 evidence-based guideline for the management of high blood pressure in adults: report from the panel members appointed to the Eighth Joint National Committee (JNC 8). JAMA 2014;311:507-520.

11. Northridge ME. Public health methods--attributable risk as a link between causality and public health action. Am J Public Health 1995;85:1202-1204.

12. Kim AS, Johnston SC. Global variation in the relative burden of stroke and ischemic heart disease. Circulation 2011;124:314323.

13. United Nations DoEaSA. World Population Prospects: The 2012 Revision. Web site http://esa.un.org/wpp/ Accessed January, 2014.

14. Nakayama T, Yokoyama T, Yoshiike N, Zaman MM, Date C, Tanaka H, et al. Population attributable fraction of stroke incidence in middle-aged and elderly people: contributions of hy- 
pertension, smoking and atrial fibrillation. Neuroepidemiology 2000;19:217-226.

15. Martiniuk AL, Lee CM, Lawes CM, Ueshima H, Suh I, Lam $\mathrm{TH}$, et al. Hypertension: its prevalence and population attributable fraction for mortality from cardiovascular disease in the Asia-Pacific region. J Hypertens 2007;25:73-79.

16. Woodward M, Zhang X, Barzi F, Pan W, Ueshima H, Rodgers A, et al. Smoking, quitting, and the risk of cardiovascular disease among women and men in the Asia Pacific region. Int J Epidemiol 2005;34:1036-1045.

17. Zhang X, Patel A, Horibe H, Wu Z, Barzi F, Rodgers A, et al. Cholesterol, coronary heart disease, and stroke in the Asia Pacific region. Int J Epidemiol 2003;32:563-572.

18. Kim BJ, Park JM, Kang K, Lee SJ, Ko Y, Kim JG, et al. Case characteristics, hyperacute treatment, and outcome information from the Clinical Research Center for Stroke-fifth division registry in South Korea. J Stroke 2015; 17:38-53.

19. Sturgeon JD, Folsom AR, Longstreth WT, Jr., Shahar E, Rosamond WD, Cushman M. Risk factors for intracerebral hemorrhage in a pooled prospective study. Stroke 2007;38:2718-2725.

20. Kweon S, Kim Y, Jang MJ, Kim K, Choi S, Chun C, et al. Data resource profile: the Korea National Health and Nutrition Examination Survey (KNHANES). Int J Epidemiol 2014;43:69-77.

21. Kelsey J, Whittemore A, Evans A, Thompson W. Methods in Observational Epidemiology. 2nd ed. New York, NY: Oxford University Press, Inc., 1996;37-39.

22. Daly LE. Confidence limits made easy: interval estimation using a substitution method. Am J Epidemiol 1998;147:783-790.

23. Lackland DT, Roccella EJ, Deutsch AF, Fornage M, George MG, Howard G, et al. Factors influencing the decline in stroke mortality: a statement from the American Heart Association/ American Stroke Association. Stroke 2014;45:315-353.

24. Feigin VL, Lawes CM, Bennett DA, Barker-Collo SL, Parag V. Worldwide stroke incidence and early case fatality reported in 56 population-based studies: a systematic review. Lancet Neurol 2009;8:355-369.

25. Korean Statistical Information Service (KOSIS). Annual report on the cause of death statistics. Web site http://kosis.kr/ Accessed March, 2015.

26. Jee SH, Suh I, Kim IS, Appel LJ. Smoking and atherosclerotic cardiovascular disease in men with low levels of serum cholesterol: the Korea Medical Insurance Corporation Study. JAMA 1999;282:2149-2155.

27. Jee SH, Park J, Jo I, Lee J, Yun S, Yun JE, et al. Smoking and atherosclerotic cardiovascular disease in women with lower levels of serum cholesterol. Atherosclerosis 2007;190:306-312.

28. Park TH, Kim MK, Lee KB, ParkJM, Lee SJ, Jung KH, et al. Population attributable risk of major risk factors for ischemic stroke in the Korean population. Korean J Stroke 2008;10:125-133.

29. Hajat C, Tilling K, Stewart JA, Lemic-Stojcevic N, Wolfe CD. Ethnic differences in risk factors for ischemic stroke: a European case-control study. Stroke 2004;35:1562-1567.

30. Kubo M, Hata J, Doi Y, Tanizaki Y, Iida M, Kiyohara Y. Secular trends in the incidence of and risk factors for ischemic stroke and its subtypes in Japanese population. Circulation 2008;118: 2672-2678.

31. Peters SA, Huxley RR, Woodward M. Smoking as a risk factor for stroke in women compared with men: a systematic review and meta-analysis of 81 cohorts, including 3,980,359 individuals and 42,401 strokes. Stroke 2013;44:2821-2828.

32. Kim YS, Park SS, Bae HJ, Heo JH, Kwon SU, Lee BC, et al. Public awareness of stroke in Korea: a population-based national survey. Stroke 2012;43:1146-1149.

33. Kissela BM, Khoury J, Kleindorfer D, Woo D, Schneider A, Alwell $\mathrm{K}$, et al. Epidemiology of ischemic stroke in patients with diabetes: the greater Cincinnati/Northern Kentucky Stroke Study. Diabetes Care 2005;28:355-359.

34. Almdal T, Scharling H, Jensen JS, Vestergaard H. The independent effect of type 2 diabetes mellitus on ischemic heart disease, stroke, and death: a population-based study of 13,000 men and women with 20 years of follow-up. Arch Intern Med 2004;164:1422-1426.

35. Cui R, Iso H, Yamagishi K, Saito I, Kokubo Y, Inoue M, et al. Diabetes mellitus and risk of stroke and its subtypes among Japanese: the Japan public health center study. Stroke 2011; 42:2611-2614.

36. Burn J, Dennis M, Bamford J, Sandercock P, Wade D, Warlow C. Long-term risk of recurrent stroke after a first-ever stroke. The Oxfordshire Community Stroke Project. Stroke 1994;25: 333-337.

37. Hardie K, Hankey GJ, Jamrozik K, Broadhurst RJ, Anderson C. Ten-year risk of first recurrent stroke and disability after first-ever stroke in the Perth Community Stroke Study. Stroke 2004;35:731-735.

38. Weimar C, Cotton D, Sha N, Sacco RL, Bath PM, Weber R, et al. Discontinuation of antiplatelet study medication and risk of recurrent stroke and cardiovascular events: results from the PRoFESS study. Cerebrovasc Dis 2013;35:538-543.

39. Go AS, Mozaffarian D, Roger VL, Benjamin EJ, Berry JD, Blaha MJ, et al. Heart disease and stroke statistics-2014 update: a report from the American Heart Association. Circulation 2014; 129:e28-e292.

40. Park TH, Ko Y, Lee SJ, Lee KB, Lee J, Han MK, et al. Gender differences in the age-stratified prevalence of risk factors in Korean ischemic stroke patients: a nationwide stroke registry-based cross-sectional study. Int J Stroke 2014;9:759- 765. 
41. Andersen KK, Olsen TS. The obesity paradox in stroke: lower mortality and lower risk of readmission for recurrent stroke in obese stroke patients. Int J Stroke 2015;10:99-104.

42. Doehner W, Schenkel J, Anker SD, Springer J, Audebert HJ. Overweight and obesity are associated with improved survival, functional outcome, and stroke recurrence after acute stroke or transient ischaemic attack: observations from the TEMPiS trial. Eur Heart J 2013;34:268-277.

43. Park JM, Cho YJ, Lee KB, Park TH, Lee SJ, Han MK, et al. Internet-based control recruitment for a case-control study of major risk factors for stroke in Korea: lessons from the experience. J Stroke Cerebrovasc Dis 2014;23:2559-2565. 
Supplementary Table 1. Comparison of stroke population from the Clinical Research Center for Stroke-5 (CRCS-5) and from the Health Insurance Review and Assessment Service (HIRA)

\begin{tabular}{lcc}
\hline & CRCS- $5(n=5,274)$ & HIRA $(n=5,264)^{*}$ \\
\hline Mean age (SD), year & $67.6(12.5)$ & $68.0(12.6)$ \\
$18 \leq,<30(\%)$ & 0.3 & 0.4 \\
$30 \leq,<45(\%)$ & 4.3 & 3.7 \\
$45 \leq,<60(\%)$ & 19.7 & 20.8 \\
$60 \leq,<75(\%)$ & 44.2 & 40.9 \\
$75 \leq,<90(\%)$ & 30.0 & 32.6 \\
$90 \leq(\%)$ & 1.5 & 1.6 \\
Male $(\%)$ & 58 & 57 \\
Onset to arrival time (hour) $\%$ & & \\
$\leq 3$ & 28.3 & 36.2 \\
$3<, \leq 6$ & 13 & 14.5 \\
$6<, \leq 12$ & 13.3 & 14.6 \\
$12<, \leq 24$ & 12.8 & 14 \\
$24<$ & 32.6 & 20.7 \\
\hline
\end{tabular}

*Acute ischemic stroke patients $(n=5,264)$ who admitted ER of 201 nation-wide hospitals between Jan. 2010-Mar. 2010 were assessed by HIRA. 
Supplementary Table 2. Odds ratios and population attributable risks according to age groups for atherosclerotic stroke and non-atherosclerotic stroke

\begin{tabular}{|c|c|c|c|c|c|}
\hline \multirow{2}{*}{ Risk factor } & \multirow{2}{*}{ Age } & \multicolumn{2}{|c|}{ Atherosclerotic stroke* } & \multicolumn{2}{|c|}{ Non-atherosclerotic stroke ${ }^{\dagger}$} \\
\hline & & Adjusted OR (95\% CI) & $\operatorname{PAR}(95 \% \mathrm{CI}), \%$ & Adjusted OR (95\% CI) & $\operatorname{PAR}(95 \% \mathrm{CI}), \%$ \\
\hline \multirow[t]{3}{*}{ Hypertension } & $\leq 45$ & $4.76(2.19,10.35)$ & $23.32(8.78,43.07)$ & $2.42(1.06,5.51)$ & $10.31(0.51,26.74)$ \\
\hline & $46-65$ & $2.07(1.67,2.57)$ & $27.01(18.82,35.15)$ & $1.51(1.17,1.96)$ & $14.99(5.45,24.82)$ \\
\hline & $\geq 66$ & $1.57(1.32,1.88)$ & $25.26(15.84,34.04)$ & $1.62(1.30,2.01)$ & $26.65(14.99,37.35)$ \\
\hline \multirow[t]{3}{*}{ DM } & $\leq 45$ & $2.32(0.79,6.80)$ & $3.53(-0.59,13.87)$ & $4.56(1.19,17.43)$ & $8.99(0.53,31.33)$ \\
\hline & $46-65$ & $2.47(1.93,3.15)$ & $15.9(10.71,21.71)$ & $1.34(0.98,1.84)$ & $4.22(-0.28,9.80)$ \\
\hline & $\geq 66$ & $2(1.66,2.42)$ & $17.33(12.10,22.89)$ & $1.51(1.20,1.90)$ & $9.63(3.99,15.84)$ \\
\hline \multirow[t]{3}{*}{$H \mathrm{~L}$} & $\leq 45$ & $2.32(0.89,6.05)$ & $6.7(-0.61,21.59)$ & $1.13(0.49,2.62)$ & $0.7(-2.88,8.14)$ \\
\hline & $46-65$ & $1.09(0.86,1.37)$ & $1.37(-2.36,5.72)$ & $1.13(0.83,1.55)$ & $2.12(-2.89,8.25)$ \\
\hline & $\geq 66$ & $1.31(1.07,1.61)$ & $5.12(1.16,9.56)$ & $1.35(1.04,1.75)$ & $5.7(0.70,11.46)$ \\
\hline \multirow[t]{3}{*}{ Smoking } & $\leq 45$ & $3.02(1.51,6.06)$ & $40.24(14.48,62.75)$ & $2.08(0.99,4.37)$ & $26.42(-0.33,52.85)$ \\
\hline & $46-65$ & $2.82(2.21,3.60)$ & $32.64(24.35,40.89)$ & $1.62(1.22,2.16)$ & $14.17(5.44,23.58)$ \\
\hline & $\geq 66$ & $2(1.60,2.51)$ & $14.21(8.96,19.99)$ & $0.94(0.71,1.25)$ & $-0.97(-5.04,3.97)$ \\
\hline \multirow[t]{3}{*}{ Stroke history } & $\leq 45$ & $2.11(0.22,20.31)$ & $0.13(-0.09,2.15)$ & Non estimated & - \\
\hline & $46-65$ & $7(4.42,11.08)$ & $10.05(5.99,15.80)$ & $7.52(4.14,13.65)$ & $10.82(5.52,19.06)$ \\
\hline & $\geq 66$ & $4.68(3.58,6.12)$ & $18.08(13.39,23.50)$ & $4.78(3.44,6.64)$ & $18.46(12.74,25.27)$ \\
\hline \multirow[t]{3}{*}{ CHD } & $\leq 45$ & Non estimated & - & $1.86(0.18,19.16)$ & $0.28(-0.27,5.66)$ \\
\hline & $46-65$ & $1.34(0.83,2.17)$ & $0.92(-0.47,3.08)$ & $2.87(1.65,5.02)$ & $4.84(1.72,9.83)$ \\
\hline & $\geq 66$ & $1.39(1.00,1.93)$ & $2.16(-0.02,5.04)$ & $3.41(2.36,4.91)$ & $12.05(7.21,18.20)$ \\
\hline \multicolumn{6}{|l|}{$\mathrm{BMI}\left(\mathrm{kg} / \mathrm{m}^{2}\right)$} \\
\hline \multirow[t]{3}{*}{$<18.5$} & $\leq 45$ & $1.44(0.32,6.46)$ & $2.72(-4.57,25.95)$ & $0.74(0.19,2.96)$ & $-1.69(-5.52,11.16)$ \\
\hline & $46-65$ & $1.23(0.58,2.62)$ & $0.46(-0.87,3.18)$ & $1.8(0.81,4.02)$ & $1.61(-0.39,5.79)$ \\
\hline & $\geq 66$ & $0.98(0.69,1.40)$ & $-0.09(-1.50,1.86)$ & $1.4(0.90,2.18)$ & $1.87(-0.47,5.30)$ \\
\hline \multirow[t]{3}{*}{$25.0-29.9$} & $\leq 45$ & $1.23(0.64,2.37)$ & $13.06(-31.13,47.25)$ & $1.36(0.72,2.56)$ & $19.01(-22.39,50.54)$ \\
\hline & $46-65$ & $0.76(0.62,0.95)$ & $-16.77(-30.50,-3.33)$ & $0.84(0.64,1.12)$ & $-10.57(-28.56,6.75)$ \\
\hline & $\geq 66$ & $0.74(0.61,0.89)$ & $-19.67(-32.56,-7.15)$ & $0.68(0.53,0.87)$ & $-25.34(-41.79,-9.29)$ \\
\hline \multirow[t]{3}{*}{$\geq 30.0$} & $\leq 45$ & $1.77(0.46,6.81)$ & $15.42(-14.79,58.01)$ & $1.97(0.54,7.19)$ & $18.71(-12.31,59.53)$ \\
\hline & $46-65$ & $0.69(0.38,1.28)$ & $-11.48(-26.42,8.53)$ & $0.8(0.36,1.76)$ & $-7.36(-27.29,20.29)$ \\
\hline & $\geq 66$ & $0.59(0.37,0.94)$ & $-13.58(-22.45,-1.74)$ & $0.98(0.54,1.80)$ & $-0.52(-15.52,18.77)$ \\
\hline
\end{tabular}

${ }^{*}$ Atherosclerotic stroke indicates the ischemic stroke attributed to large artery disease or small vessel occlusion according to the Trial of Org 10172 in Acute Stroke Treatment (TOAST); 'Non-atherosclerotic stroke indicates the ischemic stroke attributed to cardioembolism, other determined etiology, and unknown causes despite extensive routine diagnostic testing according to the TOAST.

$\mathrm{DM}$ indicates diabetes mellitus; $\mathrm{HL}$, hypercholesterolemia; $\mathrm{CHD}$, coronary heart disease; $\mathrm{BMI}$, body mass index. 